Elsevier required licence: (C) 2019

This manuscript version is made available under the CC-BY-NC-ND 4.0 license http://creativecommons.org/licenses/by-nc-nd/4.0/

The definitive publisher version is available online at

https://doi.org/10.1016/j.compositesb.2018.12.007 


\section{Accepted Manuscript}

Experimental and analytical investigation on CFRP strengthened glulam laminated timber beams: Full-scale experiments

Abbas Vahedian, Rijun Shrestha, Keith Crews

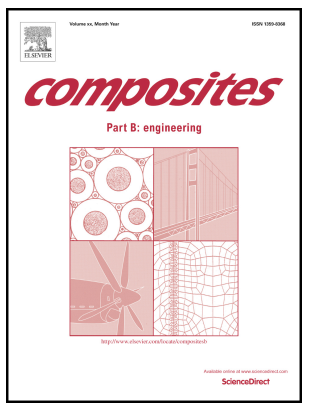

PII:

S1359-8368(18)32600-3

DOI: https://doi.org/10.1016/j.compositesb.2018.12.007

Reference: JCOMB 6336

To appear in: Composites Part B

Received Date: 13 August 2018

Revised Date: 28 November 2018

Accepted Date: 3 December 2018

Please cite this article as: Vahedian A, Shrestha R, Crews K, Experimental and analytical investigation on CFRP strengthened glulam laminated timber beams: Full-scale experiments, Composites Part $B$ (2019), doi: https://doi.org/10.1016/j.compositesb.2018.12.007.

This is a PDF file of an unedited manuscript that has been accepted for publication. As a service to our customers we are providing this early version of the manuscript. The manuscript will undergo copyediting, typesetting, and review of the resulting proof before it is published in its final form. Please note that during the production process errors may be discovered which could affect the content, and all legal disclaimers that apply to the journal pertain. 


\title{
Experimental and analytical investigation on CFRP strengthened glulam laminated timber beams: Full-scale experiments
}

\author{
Abbas Vahedian ${ }^{1}$, Rijun Shrestha, Keith Crews
}

Abbas Vahedian, School of Civil and Environmental Engineering, University of Technology, Sydney, Australia. abbas.vahedian@student.uts.edu.au

Dr Rijun Shrestha, School of Civil and Environmental Engineering, University of Technology, Sydney, Australia. Rijun.Shrestha-1@uts.edu.au

Prof Keith Crews, School of Civil and Environmental Engineering, University of Technology, Sydney, Australia. Keith.Crews@uts.edu.au

\section{ABSTRACT}

Timber is one of the most appealing and aesthetic construction materials with excellent characteristics compared with other construction materials such as steel, concrete and clay bricks. It is one of the oldest sustainable construction materials and still continues to be a popular choice in modern infrastructure. In recent years, fibre reinforced polymers (FRP) has emerged to improve mechanical properties even further. In this study, results of experimental tests on strengthened glulam beams have been used to investigate potential parameters affecting flexural strength and ultimate load carrying capacity of glulam beams strengthened with externally bonded FRP sheets. Eight full-scale timber beams with and without FRP reinforcement were tested where the bonded length, width, and thickness of the FRP was varied for FRP strengthened beams. The test results pointed out that reduction of stress concentrations can enhance the mechanical performance of the strengthened beams. The ultimate load carrying capacity and flexural strength of reinforced beams improved significantly when bond length and bond width increased. Results of

\footnotetext{
${ }^{1}$ Corresponding author. Address: Faculty of Engineering and Information Technology, School of Civil and Environmental Engineering, the University of Technology, Sydney (UTS), Sydney 2007, NSW, Australia. Tel.: +61 451118680 .
} 
experiments showed that further increase in bond thickness predominantly improves stiffness and ductility of the strengthened timber beams which has a significant enhancement in ultimate deflection and serviceability limit state. An analytical model has been established to determine the ultimate flexural capacity of strengthened timber beam. Satisfactory correlation is achieved between measured and predicted flexural capacity, signifying the capability of the new models.

Keyword, Glulam timber beams, Carbon fibre-reinforced polymer (CFRP), shear stress, Fourpoint bending tests, bond width and bond length. 


\section{Introduction}

Retrofitting and upgrading of infrastructure based on the use of advanced fibre reinforced polymers (FRPs) is one of the most common techniques that have been used for several decades. These method shows promise and can provide a higher level of assurance of the solidarity of a structure whilst minimising physical disturbance of the structure [1]. FRP sheets and laminates have been extensively used in repair and/or strengthening of concrete structures due to their outstanding properties such as high elastic modulus, high fatigue performance, high stiffness and strength to weight ratios and superior resistance to corrosion [2]. The interfacial bond behaviour between FRP and concrete for FRP strengthened concrete beams is well understood so far through decades of research $[3,4,5]$; however, limited studies have been performed to investigate the bond behaviour of strengthened timber beams $[6,7]$. The bond quality between timber and FRP was reported as the main concern of the retrofitted timber beams $[8,9]$. One of the most important failure mechanism of retrofitted timber beams is the premature failure due to debonding [10] which typically take place at much lower FRP strains than its ultimate strain [11]. Debonding directly affects the total integrity of the structure that limits the full utilisation of the material strength of the FRP [12], with the subsequent outcome that the ultimate capacity and desirable ductility of the structure may not be achieved. The body of knowledge with the use FRP strengthened glued laminated timber beams, glulam, is even more narrow and providing feasible guidelines or recommendations for such composite beams would be of crucial importance. Glulam, as an engineered wood product, has been used in building and construction industry for well over a century 
[13]. Figure 1 illustrates the strength of standard timber products and glulam, in which the glulam products have higher strength, higher characteristic strength $f_{k}$, and lower variance when compared with standard timber products. One reason can be associated to the distribution of natural defects in the glulam timber, as they are distributed more evenly throughout the sections resulting an increased strength of the glulam element $[14,15]$.

[Insert Figure 1 here]

The span of a timber beam is not necessarily limited to the strength of the material, but rather it is important to consider the serviceability limit state designs and capability of the completed structural element. Although glulam timber beams have been widespread and recognised internationally, they still have some important limitations. The design of glulam beam more often limited by the deflection of the beam rather than that of the strength. One way to deal with is to increase the height of the cross section of the beam; however, this approach is not always desirable and economical due to various reasons. To overcome this weakness, FRP martials can be used as a strengthening material for glulam to obtain more strength $[13,17]$.

The interaction between timber and FRP is relatively complex and is influenced by several variables. Environmental conditions, moisture content, surface treatment, poor adhesive mix and inadequate curing period or incorrect curing temperature 
significantly impact on the bond strength. Adhesive strength and its mechanical properties on the bond strength has been discussed in literature $[6,18]$. The effectiveness of adhesive bonding technique depends on the joint design, type of adhesive, properties of timber, the type of FRP used, environmental conditions and inservice conditions.

The bond strength can also be dependent on the geometry of the bond and boundary conditions, specimen alignment, timber mechanical properties, FRP width and thickness and FRP to timber width ratio $[19,20]$. Another important parameter that influences predominantly on the bond strength is the bond length; however, bond strength cannot increase further once the bond length exceeds the effective bond length [21]. On the other hand, the area of the bond can be enhanced by extending bond width which allows the load to be distributed over a larger area, and consequently relieves the stress concentration in the FRP and leading to delay in the debonding failure [22]. Furthermore, increasing the amount of reinforcement on the tension side of the timber beam results in the shift of the neutral axis position towards the tension zone, allowing greater strain in the compression region that leads to more ductile behaviour and increases bending strength [23].

The lack of literature describing effect of bond length, bond width, bond thickness and timber mechanical properties on the bond strength have motivated the work reported in this article. It is worth emphasising that the main focus of studies conducted to date is mostly to investigate the bond behaviour of the FRP attached to concrete; conversely, there are limited research studies to examine the use of FRP materials for the strengthening of timber beams considering the effect of above parameters. 
Therefore, an experimental investigation has been undertaken to focus on the bonding mechanisms between timber beam and fibre reinforced polymers.

\subsection{Previous studies}

Very limited attempts have been performed to investigate strengthening of timber beams with FRP; nevertheless, available studies in the literature are useful for the understanding of the performance of flexurally strengthened timber beams. For instance, Valluzzi, et al. [24] conducted a series of experimental tests to investigate the influence of moisture content on the bond strength of strengthened timber elements and timber moisture content has been reported as the main reason of debonding in all specimens. Moreover, in studies conducted by Lyons and Ahmed and Raftery et al. [25, 26], it was observed that the bond strength in a dry environment achieved better results compared to wet/soaked environment.

Wan et al. [27] has performed a series of tests on unstrengthened and CFRP strengthened glulam timber beams, and accordingly proposed a debonding strain model for externally strengthened timber beams. In such investigation, it was observed that all the strengthened timber beams achieved higher strength compared to unstrengthened timber beam and the load carrying capacity of CFRP timber beams was enhanced by $\% 7$ to $\% 60$. Wan [28] also conducted a more extensive study on FRPto-timber interface and concluded that the properties of the adhesives may not have a substantial impact on the interface when FRP was bonded to timber. However, this conclusion contradicts with the results obtained by Vallée et al. [18] in which samples made by stiffer adhesive experienced higher stress peaks, when compared to the 
sample made by softer adhesive. Near-surface mounted FRP technique has been investigated experimentally [29] and numerically [30] in which both studies concluded that the flexurally strengthened timber beams failed at higher level of applied loads compared to unstrengthened beams. Furthermore, in these studies, timber compressive failure occurred in the strengthened timber beams resulting in a more ductile behaviour which is desirable from a structural design point of view; whilst unstrengthened beams failed due to brittle tensile rupture. In the study conducted by De Jesus, et al. [31], it was observed that when the bond length is not long enough the improvement of strengthened beams would be negligible. The main reason for this observation can be attributed to the initiation of crack due to stress concentration at the end of the reinforcement. When the bond length is not long enough, cracks initiate and propagate at the timber-CFRP interface. After some adhesive failure, the crack deviates towards the timber, leading to the final collapse of the beam.

Despite studies conducted in strengthening of timber beams using composite materials, the knowledge of interface between timber beam and FRP is scarce and a comprehensive understating of the bond is essential. This paper presents an experimental investigation on full-scale timber beams strengthened with carbon fibre composite material. The main intention of this research study is to investigate the bond strength and bond behaviour between timber and FRP and also to scrutinise the potential factors affecting FRP-to-timber beams. Eight timber beams, with or without FRP strengthening were tested under monotonic load in four-point bending. A novel predictive model was then established to predict the flexural capacity of strengthened timber beams. The comparative analysis of the results of the experimental tests and 
those predicted from the analytical model shows a good correlation between measured and predicted strength.

\section{Material properties}

\subsection{Timber mechanical properties}

The specimens used for material tests on timber were cut from the same timber used to make the beam tests. In total, ten specimens divided into two groups have been loaded parallel and perpendicular to grain for determination of tensile and compressive strength of timber specimens. The tests include four samples in tension and three samples in compression parallel to the grain; and three samples in compression perpendicular to the grain.

Tensile and compressive strength of the timber was determined based on tests on small samples and according to BS EN 408:2010 [32]. In the compression tests parallel to grain, the specimens had the average cross-sectional dimensions of $45 \mathrm{~mm}$ by 90 $\mathrm{mm}$ and a height of $270 \mathrm{~mm}$. Timber end surfaces have been accurately prepared to make them flat and parallel to one another and perpendicular to the axis of the piece. The samples used in tension had the mean cross-sectional dimensions of $45 \mathrm{~mm} \times 90$ $\mathrm{mm}$ with the length of $900 \mathrm{~mm}$ following the recommendation of BS EN 408:2010 [32]. The load rates for the tests were determined from results of preliminary tests (two specimens for tensile strength and one sample for compressive strength). The constant uniaxial loads parallel to grain, considering results of preliminary tests, were applied 
until failure occurred in the specimens with the rates of $0.5 \mathrm{~mm} / \mathrm{min}$ and $8 \mathrm{~mm} / \mathrm{min}$ in compression and tension, respectively (refer to Figure 2). The ultimate loads have been reached within $(300 \pm 120)$ s which perfectly fitted the recommendation of BS EN 408:2010 [32]. Accordingly, the tensile and compression strength parallel to grain were determined as the peak load divided by the cross-sectional area of the specimens. Modulus of elasticity; however, was determined by Eq. (1) from three strain gauges bonded parallel and perpendicular to three sides of the test samples.

$$
M O E=\frac{L_{1}\left(F_{2}-F_{1}\right)}{A\left(W_{2}-W_{1}\right)}
$$

Where $F_{2}-F_{1}$ is an increment of load on the straight-line portion of the load deformation curve, in Newtons; $W_{2}-W_{1}$ is the increment of deformation corresponding to $F_{2}-F_{1}$. The compressive strength perpendicular to the grain can be determined from Eq. (2), where $b$ and / are width and length of specimen, respectively. The compression tests perpendicular to grain possessed the average dimensions of 45 $\mathrm{mm}$ width by $90 \mathrm{~mm}$ height and $70 \mathrm{~mm}$ long according to BS EN 408:2010 [32]. A strain gauge with gauge length of $60 \mathrm{~mm}$ located centrally in the test samples height. The samples were mounted vertically between the test machine platens and an initial load applied. To prevent rotation or angular movement, the loading-heads were locked during the test. Then, universal load concentrically applied perpendicular to grain with the rate of $0.7 \mathrm{~mm} / \mathrm{min}$; obtained from preliminary tests. The method for determining $F_{c, 90, \max }$ is given in section 19.3 of BS EN 408:2010 [129]. The test results are tabulated in Table 1, Table 2, and Table 3.

$$
f_{c, 90}=\frac{F_{c, 90, \max }}{b l}
$$


[Insert Figure 2 here]

Table 1 Compression parallel to grain

\begin{tabular}{|c|c|c|c|c|c|c|c|}
\hline \multicolumn{2}{|c|}{ Samples } & $\begin{array}{c}\mathrm{Pu} \\
(\mathrm{kN})\end{array}$ & \multicolumn{2}{|c|}{$\begin{array}{c}\text { Compressive Strength } \\
(\mathrm{MPa})\end{array}$} & \multicolumn{2}{|c|}{ MOE (GPa) } & Poisson Ratio \\
\hline \multicolumn{2}{|c|}{$\mathrm{C} 1$} & 162.28 & \multicolumn{2}{|c|}{40.07} & \multicolumn{2}{|c|}{--} & -- \\
\hline \multicolumn{2}{|c|}{$\mathrm{C} 2$} & 166.60 & \multicolumn{2}{|c|}{41.14} & \multicolumn{2}{|c|}{15.04} & -- \\
\hline \multicolumn{2}{|c|}{$\mathrm{C} 3$} & 166.63 & \multicolumn{2}{|c|}{41.14} & \multicolumn{2}{|c|}{12.08} & 0.3 \\
\hline \multicolumn{2}{|c|}{ Average } & 165.17 & \multicolumn{2}{|c|}{40.78} & \multicolumn{2}{|c|}{13.56} & 0.3 \\
\hline \multicolumn{2}{|c|}{$\mathrm{CoV}$} & $1.52 \%$ & \multicolumn{2}{|c|}{$1.52 \%$} & \multicolumn{2}{|c|}{$15.43 \%$} & -- \\
\hline \multicolumn{4}{|c|}{ Table 2 Compression perpendicular to grain } & \multicolumn{4}{|c|}{ Table 3 Tension parallel to grain } \\
\hline Samples & $\begin{array}{c}f_{c, 90, \max } \\
(\mathrm{kN})\end{array}$ & $\begin{array}{c}\text { Compressive } \\
\text { Strength } \\
(\mathrm{MPa})\end{array}$ & $\begin{array}{l}\text { MOE } \\
(\mathrm{GPa})\end{array}$ & Samples & $\begin{array}{l}\mathrm{Pu} \\
(\mathrm{kN})\end{array}$ & $\begin{array}{c}\text { Tensile } \\
\text { Strength } \\
\text { (MPa) }\end{array}$ & $\begin{array}{l}\text { MOE } \\
(\mathrm{GPa})\end{array}$ \\
\hline CP1 & 8.34 & 1.65 & -- & $\mathrm{T} 1$ & 106.34 & 26.26 & -- \\
\hline $\mathrm{CP} 2$ & 7.95 & 1.81 & 0.46 & $\mathrm{~T} 2$ & 92.65 & 22.88 & 18.22 \\
\hline $\mathrm{CP} 3$ & 9.12 & 2.01 & 0.44 & T3 & 119.59 & 29.53 & 14.53 \\
\hline Average & 8.47 & 1.89 & 0.45 & Average & 106.19 & 26.22 & 16.38 \\
\hline $\mathrm{CoV}$ & $7.02 \%$ & $9.91 \%$ & $2.23 \%$ & CoV & $12.69 \%$ & $12.69 \%$ & $15.91 \%$ \\
\hline
\end{tabular}

CoV: co-efficient of variation.

\subsection{FRP tensile tests}

The tensile tests of coupon specimens were conducted to obtain tensile strength and modulus of elasticity of CFRP. The uni-directional wet-lay up of CFRP supplied by GESS Pty Ltd with the nominal thickness of $0.167 \mathrm{~mm}$ were utilised for all FRP-to-timber beams. Prior to fabrication of the samples, surface of the FRP materials was wiped clean to remove all contaminants from surface of FRP according to ASTM-D2093-03 [33] and BSI [34]. It is worth emphasis that special care has been taken to ensure neither to break reinforcing fibres, nor to affect the bulk properties of the composite.

To fabricate the samples, two plies of the fibres with the dimension of $200 \mathrm{~mm} x$ $300 \mathrm{~mm}$ were placed in a release film and bonded with an epoxy based from Sika (Sikadur ${ }^{\circledR} 330$ ). One extra layer of FRP was applied in each side of the sample with the 
dimension of $80 \mathrm{~mm} \times 200 \mathrm{~mm}$ to provide proper thickness of end tapping, and then a release film is placed over the sample. The sample then placed in the lab to be cured for at least 14 days. The sample was then cut into the desired dimensions according to ASTM D3039/D3039M Standard [35]. Prior to tension testing, the area of the specimen was measured at three places in the gauge section using a micrometre with a flat anvil interface, and the average of these three determinations were reported as tabulated in Table 4.

Five CFRP coupons were prepared and tested with average dimensions of $0.334 \mathrm{~mm} x$ $15.0 \mathrm{~mm} \times 250 \mathrm{~mm}$ and standard head displacement rate of $2 \mathrm{~mm} / \mathrm{min}$ following the ASTM D3039/D3039M Standard [35] as shown in Figure 3. One strain gauge was bonded longitudinally in the middle of the coupon (gauge section) and the tensile strength and modulus of modulus of elasticity of the FRP can be determined from the stress verses strain curves. From tensile tests of coupon samples, the average values of 2649MPa and 245GPa have been obtained for FRP tensile strength and elastic moduli, respectively. The tensile strength and modules of elasticity specified by the manufacturer are $2600 \mathrm{MPa}$ and $210 \mathrm{GPa}$, respectively that are close to the tested specimens. The mean ultimate strain was also obtained 0.011 with a co-efficient of variation of $18.09 \%$.

Table 4 FRP tensile test results

\begin{tabular}{cccc}
\hline Samples & Tensile Strength (MPa) & MOE (GPa) & Ultimate Strain \\
\hline 1 & 2664 & 224 & 0.013 \\
2 & 2628 & 261 & 0.011 \\
3 & 2718 & 235 & 0.013 \\
4 & 2819 & 238 & 0.008 \\
5 & 2416 & 267 & 0.012 \\
\hline Average & 2649 & 245 & 0.011 \\
\hline
\end{tabular}




\begin{tabular}{llll}
\hline (CoV) & $5.62 \%$ & $7.38 \%$ & $18.09 \%$ \\
\hline CoV: co-fficient of variation & &
\end{tabular}

CoV: co-efficient of variation.

[Insert Figure 3 here]

\section{Details of test specimens}

Eight timber beams, two unstrengthened (control) and six strengthened with FRP were tested under monotonic load in four-point bending according to the AS/NZS 4063 [36] and BS EN408 Standards [32]. The timber was selected structural grade of Pine Laminated GL10 with an allowable bending strength of $22 \mathrm{MPa}$ and modulus of elasticity 10GPa (specified by the manufacturer). Tested mechanical properties of the timber, as reported in Tables 1, 2, and 3, have been used in the analytical phase of this study. All beams were $45 \mathrm{~mm}$ wide, $90 \mathrm{~mm}$ deep with the total length of $1800 \mathrm{~mm}$ and clear span of $1620 \mathrm{~mm}$. The timber beams were made of four layers of Pine - thickness of each layer was $22.5 \mathrm{~mm}$.

Six strengthening configurations were tested for the FRP strengthened beams (Table 5). Two and four layers of FRP sheet with total lengths of $1000 \mathrm{~mm}$ and $1300 \mathrm{~mm}$ and two different widths $(30 \mathrm{~mm}$ and $45 \mathrm{~mm}$ ) were attached to the tensile area of timber beams. The uni-directional FRP sheets, which had a nominal thickness of $0.167 \mathrm{~mm}$, were bonded to timber beams with an epoxy based from Sika (Sikadur ${ }^{\circledR}-330$ ) using a wet lay-up process. The fibre direction of FRP was aligned along the longitudinal direction of the timber beams. Prior to bonding FRPs, the timber surface was wiped 
clean with acetone, and surface of CFRP sheets was cleaned and prepared as per ASTM-D2093-03 [33] and BSI [34]. The epoxy-based adhesive was then applied to the surface of timber beams and FRP sheets were then laid on the adhesive. An aluminium roller was used to impregnate the FRP fibres with the epoxy as well as to remove trapped air and brush out the excessive epoxy. The epoxy adhesive was not tested; however, the values of elastic modulus and tensile strength of Sikadur ${ }^{\circledR}-330$ were taken as $4.5 \mathrm{GPa}$ and $30 \mathrm{MPa}$, respectively as per manufacture's product data sheet [37].

Table 5 Detail of the tested timber beams

\begin{tabular}{cccccccc}
\hline Identification & \multicolumn{3}{c}{ Timber Beam } & \multicolumn{3}{c}{ FRP } & $\begin{array}{c}\text { FRP-to-Timber } \\
\text { of Specimen }\end{array}$ \\
\cline { 5 - 6 } & $\begin{array}{c}\text { Length } \\
(\mathrm{mm})\end{array}$ & $\begin{array}{c}\text { Width } \\
(\mathrm{mm})\end{array}$ & $\begin{array}{c}\text { Height } \\
(\mathrm{mm})\end{array}$ & $\begin{array}{c}\text { Thickness } \\
(\mathrm{mm})\end{array}$ & $\begin{array}{c}\text { Length } \\
(\mathrm{mm})\end{array}$ & $\begin{array}{c}\text { Width } \\
(\mathrm{mm})\end{array}$ & Width Ratio (\%) \\
\hline B1 (TS1) & 3000 & 45 & 90 & N/A & N/A & N/A & N/A \\
B2 (TS2) & 3000 & 45 & 90 & N/A & N/A & N/A & N/A \\
B3 (TS3) & 3000 & 45 & 90 & $2 \times 0.167$ & 1000 & 30 & 67 \\
B4 (TS4) & 3000 & 45 & 90 & $4 \times 0.167$ & 1000 & 30 & 67 \\
B5 (TS8) & 3000 & 45 & 90 & $4 \times 0.167$ & 1300 & 30 & 67 \\
B6 (TS5) & 3000 & 45 & 90 & $2 \times 0.167$ & 1000 & 45 & 100 \\
B7 (TS7) & 3000 & 45 & 90 & $2 \times 0.167$ & 1300 & 45 & 100 \\
B8 (TS6) & 3000 & 45 & 90 & $4 \times 0.167$ & 1300 & 45 & 100 \\
\hline
\end{tabular}

\section{Detail of test setup and procedure}

Figure 4 shows the schematic diagram of the four-point bending test setup where the end supports were designed to simulate a pin and a roller configuration; also, the photograph tests in progress are shown Figure 5. Each beam had an overall length of 20 times the depth of the section and the length of the test span was 18 times the depth of the section. Bearing plates were placed at the loading points and supports to prevent crushing indentation. Load was applied symmetrically at the third points of the test span using a universal testing machine (UTM) which had a capacity of $500 \mathrm{kN}$. Maximum load range of $30 \mathrm{kN}$ was applied based on predicted load capacity of sample 
tests as well as results of preliminary test samples which were in the range of 10-12 $\mathrm{kN}$. Load was applied at the constant rate of $0.15 \mathrm{~mm} / \mathrm{s}(9 \mathrm{~mm} / \mathrm{min})$ until failure occurred; where the maximum load was reached within $300 \pm 120$ s. AS/NZS 4063 [36] and BS EN408 [32] were followed for the test setup and procedure.

A Laser Displacement Sensor (LDS) was mounted underneath of the beams at the midspan to determine mid-span deflection of the tested beams. For FRP strengthened beams, strain gauges were attached to the FRP surface to measure the strain variation along the FRP length. A mix of strain gauges with $60 \mathrm{~mm}$ and $10 \mathrm{~mm}$ gauge lengths and $120.3 \pm 0.5 \Omega$ resistance were bonded to the surface of CFRP. In total, eight strain gauges were used in specimens with $1000 \mathrm{~mm}$ bond length; while for samples with $1300 \mathrm{~mm}$ bond length, nine strain gauges were bonded to the centreline of the FRP sheets along the bonded length (Figure 4). Since the bond length varies, the last strain gauge was placed near the end of the bond to measure strain at this point.

[Insert Figure 4 here]

[Insert Figure 5 here] 


\section{$5 \quad$ Analysis and discussion of the experimental results}

\subsection{Failure modes of the samples}

The behaviour of timber in bending highly depends on the relative values of compression and tension strengths. The ratio of tension to compression strength of timber materials used herein is $64 \%$. Thus, due to lower tension strength of unstrengthened timber beams, tension zone was subjected to the maximum moment and a brittle tension failure occurred in both unstrengthened beams without compressive failure as shown in Figure 6 (a). However, experimental tests of strengthened beams showed that failure may occur with partial plasticisation of the compressed zone because of natural defect like knot followed by failure at tension zone as shown in Figure 6 (b). Besides, when the bond length was not long enough, the failure mechanism was associated due to crack initiation at the end of the FRP reinforcement followed by its propagation through interface leading strengthened timber beams ultimately fail in tension as shown in Figure 6 (b). The main reason for this observation can be attributed to the initiation of crack due to stress concentration at the end of the reinforcement. On the other hand, in specimens where the bond length was $1300 \mathrm{~mm}$, beams failed in a more ductile manner and the observed failure mode was associated to split of timber beams due to shear failure between the load and support point as illustrated in Figure 6 (d). No delamination occurred between timber beams and FRP during experimental tests. FRPs sheets remained undamaged and no rupture observed in the fibres as expected; the maximum strain measured in 
the FRP was around $75 \%$ of the minimum ultimate strains of FRPs achieved from coupon tests.

[Insert Figure 6 here]

\subsection{Load-deflections of the samples}

The load-displacement plot for beams B1 to B8 at the mid-span are shown in Figure 7. The ultimate load and the corresponding mid-span deflection at ultimate load of the beams are listed in Table 6 . The load-displacement response of the control beams was almost linear up to failure, and then beams collapsed suddenly in a brittle manner without prior indication warning that collapse is imminent. It is obvious that the reinforcement leads to increase stiffness of composite beams. As a result, the strengthened beams exhibited an initial linear increase in the load-displacement response. After such, the response becomes nonlinear with a continuous increase in the applied load and then the curve fluctuates near a constant load until failure. At this point, the ultimate load that can be carried by the FRP plate is attained and simultaneously, the effective bond zone shifts toward end of beam. Therefore, the ultimate load $\left(P_{u}\right)$ remains almost constant and the beams failed in a ductile manner. Figure 7 and Table 6 illustrate that there is a significant increase in both strength and stiffness when FRPs are bonded to timber. As can be seen, the mid-span deflection of the control beams at failure were approximately $29 \mathrm{~mm}$ and $26 \mathrm{~mm}$ for beams B1 and B2, respectively; whereas, the mid-span displacement of the FRP strengthened beams corresponding to the same level of applied load were around $19 \mathrm{~mm}$ to $13 \mathrm{~mm}$ for 
beams $B 3$ and $B 8$, respectively. The analysis of the table shows that the stiffness values of strengthened beams increased by around 31\% for $1000 \mathrm{~mm}$ reinforcement; whilst; longer reinforcements $(1300 \mathrm{~mm})$ provided around $45 \%$ increase in stiffens when compared with control beams. In addition, results of beams B8 and B5 demonstrate that the more bond width, the more stiffness can be achieved, where the stiffness of beams $\mathrm{B} 5$ and $\mathrm{B} 8$ were recorded $43 \%$ and $64 \%$, respectively.

\subsection{Effect of FRP thickness on strengthened beams}

Results of the tested beams obviously show that the lowest strength is associated to the reference specimens (peak load $7.86 \mathrm{kN}$ ); while strengthened beams carried out higher level of load where the maximum load $(19.48 \mathrm{kN})$ was recorded for beams B8. The ultimate load in beams B3 and B4 increased by $43 \%$ and $52 \%$, respectively with respect to unstrengthened condition. It is important to note that the width and length of FRP for these two beams were identical; however, two and four layers of FRP were bonded to beams B3 and B4, respectively. It can be seen that with increase of bond thickness by two times, the load carrying capacity increased, although this increase is not prominent. However, the increase of bond thickness promotes the stiffness of strengthened beam leading to decrease deflection of strengthened beams. For instance, around $29 \mathrm{~mm}$ displacement was recorded for beam B3 at failure; whilst, at the same level of applied load around $24 \mathrm{~mm}$ mid-span deflection was recorded for beams B4 which is approximately $18 \%$ reduction in mid-span displacement at the same level of load. This result can be a sound improvement in the serviceability limit state. 


\subsection{Effect of FRP width on strengthened beams}

Bending strength significantly enhanced when width of interface increased. To investigate the effect of bond width on the load carrying capacity of the beam, results of beams B3 and B4 can be compared with beam B6 in such bond width was equal to width of timber beam ( $45 \mathrm{~mm}$ ). As can be seen in Table 6 and Figure 7, the ultimate load of beam B6 increased by around $90 \%$ which is more than double of the increased load achieved in beam B3. Beam B6 is even more robust than beam B4 in which 4 layers of FRP were used. Similar trend observed when beam B8 compared to beam B5, in such all bond characteristic and timber cross-section were identical except the width FRP. This finding signifies that with the increase of the FRP width, the bond strength increases. One reason can be highlighted that when FRP-to-timber width ratio is low, the force transfers from the FRP to timber leads to a non-uniform stress distribution across the width of timber leading to interfacial failure at lower load level. In addition, a smaller FRP width compared to the timber width may result in a higher stress in the bond at failure; directing stress from bonded area to the timber outside of the bonded zone. These findings are consistent with the previous studies conducted by $[22,38]$.

\subsection{Effect of bonded length on strengthened beams}

Results of beams B4, B5, B6 and B7 highlight that the bond length significantly impacts on the bending strength and load carrying capacity of strengthened beam. The bond length in beams B5 and B7 were $300 \mathrm{~mm}$ longer than beams B4 and B6. As shown in Figure 7, beams B7 and B5 failed at higher level of loads (18.29 kN and $17.25 \mathrm{kN})$ when compared with beams B6 and B4 (14.92 kN and $11.91 \mathrm{kN})$, respectively. At the lower 
level of applied load, it was observed that both test series have similar initial stiffness values; however, the ultimate loads were higher on the series with longer reinforcement and the mid-span deflection decreased when bond length increased. As mentioned earlier, the typical failure mode in test series with the smaller reinforcement length was characterised by cracks initiating at the end of the reinforcement due to stress concentration followed by brittle failure of beams. However, when the bond length was long enough, the stress distributed in a large area leading to reduce shear stress in the bond and consequently resulting to increase the strength of timber beam. This finding agrees to the observation reported in [31] which signifies that the stiffness of beams strengthened with longer FRP was higher than that of those beams strengthened with shorter FRP. However, it is worth emphasising that effective bond length must always be taken into consideration, since many studies [21, $39,40]$ have confirmed that the bond strength cannot increase further once the bond length exceeds the effective bond length. Nevertheless, a longer bond length can improve the ductility [38].

[Insert Figure 7 here] 
Table 6 Experimental results from the beams tested

\begin{tabular}{|c|c|c|c|c|c|c|c|c|c|c|c|}
\hline Member & $\begin{array}{l}\text { FRP } \\
\text { Layers } \\
\text { No. }\end{array}$ & $\begin{array}{l}\text { FRP Width } \\
\quad(\mathrm{mm})\end{array}$ & $\begin{array}{c}\text { FRP } \\
\text { length } \\
(\mathrm{mm})\end{array}$ & $\begin{array}{l}\text { Peak } \\
\text { load } \\
(\mathrm{kN})\end{array}$ & $\begin{array}{l}\text { Maximum } \\
\text { bending } \\
\text { moment } \\
(\mathrm{kN} . \mathrm{m})\end{array}$ & $\begin{array}{l}\text { Maximum } \\
\text { bending } \\
\text { stress } \\
(\mathrm{MPa})\end{array}$ & $\begin{array}{c}\text { Maximum } \\
\text { mid-span } \\
\text { displacement } \\
(\mathrm{mm})\end{array}$ & $\begin{array}{c}\text { Stiffness } \\
\left(\text { EI) } * 10^{9}\right. \\
\text { N.mm }\end{array}$ & $\begin{array}{l}\text { Modulus of } \\
\text { elasticity } \\
\text { (MOE) (MPa) }\end{array}$ & $\begin{array}{l}\text { Increase } \\
\text { in peak } \\
\text { load (\%) }\end{array}$ & $\begin{array}{l}\text { Increase in } \\
\text { stiffness (\%) }\end{array}$ \\
\hline B1 & -- & -- & -- & 6.82 & 1.84 & 30.30 & 29.15 & 17.65 & 6455.16 & $\mathrm{~N} / \mathrm{A}$ & $\mathrm{N} / \mathrm{A}$ \\
\hline B2 & -- & -- & --- & 7.86 & 2.12 & 34.93 & 26.22 & 22.62 & 8273.02 & N/A & N/A \\
\hline B3 & 2 & 30 & 1000 & 11.22 & 3.03 & 43.75 & 29.11 & 29.52 & 9746.12 & 0.43 & 0.31 \\
\hline B4 & 4 & 30 & 1000 & 11.91 & 3.22 & 41.38 & 28.76 & 31.50 & 9524.92 & 0.52 & 0.39 \\
\hline B5 & 4 & 30 & 1300 & 17.75 & 4.79 & 61.66 & 41.59 & 32.43 & 9804.53 & 1.26 & 0.43 \\
\hline B6 & 2 & 45 & 1000 & 14.92 & 4.03 & 54.61 & 38.20 & 29.73 & 9383.45 & 0.90 & 0.31 \\
\hline B7 & 2 & 45 & 1300 & 18.29 & 4.94 & 66.96 & 46.87 & 32.80 & 10352.39 & 1.33 & 0.45 \\
\hline B8 & 4 & 45 & 1300 & 19.48 & 5.26 & 60.70 & 39.44 & 37.13 & 10414.40 & 1.48 & 0.64 \\
\hline
\end{tabular}




\subsection{Strain distributions in the FRP sheets}

The maximum strain observed in the FRP bonded to the timber beams was $0.6 \%$ and was at the mid-span of beams B5 as shown in Figure 8. The level of FRP strain observed in the four-point bending tests was much lower than the strain in FRP at ultimate limit state recorded during the FRP coupon tests (refer to Figure 3). This observation indicates that the bending strength of reinforced timber beam is not limited by the tensile strength of fibre composites; but. timber mechanical properties, bond geometries and the interfacial strength are the main parameters that impact on the flexural strength of the strengthened timber beam.

Figure 8 shows strain distribution profiles along bonded length at various load levels for selected beams where the bond widths were $30 \mathrm{~mm}$ and $45 \mathrm{~mm}$, and two and four layers of FRP were bonded to timber beams. The obtained strain distributions are rather similar to the bending moment diagram of the four-point bending test, with a bilinear tendency that is constant between applied loads, and a linear portion between loads and supports. The dissimilar strain distribution diagrams (refer to Figure 8 ) in either sides of mid-span is different from the theoretical relationship between the FRP sheet strain and the distance from the mid-span, since it is expected to be identical for completely homogeneous material. This phenomenon may be due to material heterogeneity or stress concentration in the FRP plate and timber at a meso-scale. Moreover, it may not be always possible to continuously measure accurate strain in the interface, since timber failure or failure at interface may lead to strain gauges detach from the surface of FRP preventing further measurement of strains. 
It is worth emphasis that specimens strengthened with $30 \mathrm{~mm}$ bond width failed at lower level of loads; however, it was observed that maximum strain in such sample at failure was higher than that of samples strengthened with $45 \mathrm{~mm}$ of FRP as shown in Figure 8 . Although all results are not shown here, this difference has been observed in all samples when recorded strain in specimens with $30 \mathrm{~mm}$ bond width compared with specimens with $45 \mathrm{~mm}$ bond width. This observation can be related to the stiffness and modulus of elasticity of composite beams; in which due to lower stiffness and elastic modulus of composite beams, more mid-span deflection with higher strain can be expected being occurred resulting a higher shear stress in the bond at failure. In addition, since the width of FRP is lower than that of timber width, the stress shifts over a partial active area leading to local shear stress concentrations which may results a higher strain at failure. Furthermore, the strain distribution profile of beams B7 and B8 show that higher stiffness of interface reduces strain at failure; although the obtained ultimate load of both beams was relatively similar. It is important to note that, all bond characteristic and timber cross-section of beams B7 and B8 were identical except that bond thickness where beams B7 and B8 were strengthened with two and four layers of FRP, respectively. Theoretically, if the reinforcement ratio in the tension zone is adequate and large enough, the failure mode changes from a brittle tensile to a more ductile compression, since the neutral axis position moves downward leading lower stress and strain in the tension area and, conversely higher strain in the compressive area. The part of timber yielding in compression spreads from the top of the beam to the bottom until the beam ultimately fails by tensile disconnection/rupture of the bottom wooden fibres. Therefore, more efficient use is 
made of the compressive strength of the timber. This transition in failure mode leads substantial enhance in capacity and ductility of the strengthened beam. Simultaneously, as the FRP reinforcement prevents crack opening and restricts local rupture, the average ultimate tensile strength of the timber typically increases.

[Insert Figure 8 here] 


\subsection{Bond stress distributions in the FRP sheets}

The average interfacial bond stress or shear stress distribution within the strengthened beam can be determined from two consecutive strain gauge positions as follows [41]:

$\tau_{i-j}=t_{f} \cdot E_{f} \cdot \frac{\left(\varepsilon_{i}-\varepsilon_{j}\right)}{\Delta l_{i-j}}$

In Eq. (3), $\varepsilon_{i}$ and $\varepsilon_{j}$ are two strain gauges at positions $i$ and $j$, and $\Delta l_{i-j}$ is the distance between these two gauges. Figure 9 illustrates interfacial bond stress as function of relative load and bond length for beams B4 to B7. As can be seen, beam B4 experienced higher level of stress at failure; whilst, at the same level of applied load, lower interfacial bond stress has been obtained in specimen B5. Similar trend observed, when Beam B6 compared with beam B7. It is important to note that, bond length is the only distinguished difference in beams B4 and B5, as well as beam B6 and B7. When the bond length was shorter than the effective bond length, crack may have formed in the bond at lower strain leading debonding in the interface. Nevertheless, as the applied load on FRP plate increases, crack along the interface propagates and simultaneously the region of high stress transferred from one area to the adjacent area until the total debonding of the bond occurs. Therefore, at the same time, only limited area of the bond activates and the applied load is carried by this area. When such active area reaches the end of bonded interface, the bond shear stress increases, since the FRP reinforcement no longer contributes to the flexural stiffness of the section and any increase in applied load must be carried by the timber beam. As a result, since the ultimate bending strength of pure timber beam is significantly lower than that of strengthened beam, failure occurs abruptly. Therefore, it can be 
concluded that bond length has a major contribution in shear stress distribution in the interface that directly impacts on the bending strength as well as failure mode of strengthened timber beams.

Theoretically, in the four-point bending test, the axial bond stress at both sides of the mid-span is expected to be identical for completely homogeneous material; however, there is a noticeable spatial variation in the interfacial bond stress derived from sampling tests as shown in Figure 9. These fluctuations in the bond stress can be related to material heterogeneity in the FRP sheets and timber at a meso-scale. Figure 9 also shows that shear stress between applied loads are relatively low; whereas the interfacial bond stress between loading points and supports are more pronounced. This trend can be attributed to the fact that in the four-point bending test, the bending moment between mechanical loading is constant and accordingly, the strains are constant likewise. Consequently, using Eq. (3), a constant strain distribution leads to zero interfacial bond stress.

Figure 10 shows the relationship between interfacial bond stress and bond width at various load levels expressing that the shear stress decreases with the increase of FRPto-timber width ratio. Higher bond stress has been achieved in specimens B3 and B5 when compared with beams B6 and B8, respectively. It is worth emphasising the FRPto-timber width ratio for specimens B3 and B5 was $67 \%$, whilst, such ratio for beams B6 and B8 was 100\%. Although, in the current study strain gauges were not bonded in the transverse direction, it has been proven that when FRP to timber width ratio is low, the force transfers from the FRP to timber leads to a non-uniform stress distribution across the width of timber resulting in a higher shear stress in the bond at failure [38]. 
Therefore, with increase of FRP width, the interfacial bond strength increases, leading to a decrease of slip during the softening-debonded stage. This finding is in agreement with the previous studies when the FRP was bonded to concrete [22, 42, 43].

[Insert Figure 9 here]

[Insert Figure 10 here] 


\section{Prediction of ultimate moment capacity of CFRP- strengthened timber beam}

With reference to the prediction model proposed by Borri et al. [23] and following assumptions, an analytical model based on a cross-section analysis (as shown in Figure 11) is developed to predict the flexure capacity of timber beam strengthened with CFRP.

1. Timber beams are orthotropic materials with two orthogonal planes of symmetry;

2. Bazan-Buchanan law [44] for the stress-strain relationships of timber assumed in which timber is linearly elastic until failure in tension; however, it is bilinear in compression;

3. A full composite action between timber and FRP is assumed since no debonding was observed during specimen tests;

4. As no rupture of FRP occurred during experiments, the failure of beams is defined by limit strain in timber either tension or compression.

[Insert Figure 11 here]

Where $\sigma_{t}$ is maximum timber tensile stress, $\sigma_{c t}$ is the maximum timber compression stress, $\bigoplus_{t}$ and $\bigoplus_{c t}$ are maximum strains in tension and compression, respectively. $\square_{c y}$ is the elastic limit compression strain and $\sigma_{c y}$ is the elastic timber compression stress. The tensile force in the FRP $\left(F_{f r p}\right)$ can be calculated based on the strain $\left(\square_{f r p}\right)$; in which a strain greater than 0.011 (the average ultimate strain achieved from coupon tests) 
would result in failure of the FRP. The stress distribution along the cross section is linear when maximum strains in tension is lower than strain in the elastic limit compression, $\square_{c t}<\square_{c y}$; however, plastic deformation occurs on the compression area when $a_{c y}<Q_{c t}<a_{c u}$. As such, two separate cases are considered depending on the strain in the cross section:

Case 1 if $\varepsilon_{c t} \leq \varepsilon_{c y}$

$F_{c t}=F_{t t}+F_{f r p}$

$F_{c t}=\frac{1}{2} \sigma_{c t} b_{t} y_{c}$

$F_{t t}=\frac{1}{2} \sigma_{t t} b_{t}\left(h-y_{c}\right)$

$F_{f r p}=\sigma_{f r p} b_{f r p} t_{f r p}$

$\varepsilon_{c t}=\frac{y_{c} \varepsilon_{t}}{h-y_{c}}$

From the Bazan-Buchanan law [44] when $\left.]_{c t}<\right]_{c y}$

$\sigma_{c t}=E_{t} \varepsilon_{c t}$

$\sigma_{t t}=E_{t} \varepsilon_{t}$

$\sigma_{f r p}=E_{f r p} \varepsilon_{f r p}$

The neutral axis location can be determined by substituing Eqs. ( 5 - 11) to Eq. (4) as expressed

$\frac{1}{2} E_{t} \varepsilon_{c t} y_{c} b_{t}-\frac{1}{2} E_{t} \varepsilon_{t t}\left(h-y_{c}\right) b_{t}-E_{f r p} \varepsilon_{f r p}\left(h-y_{c}+\frac{t_{f r p}}{2}\right) b_{f r p}=0$ 
Once the location of neutral axis determined from Eq. (12), the ultimate bending capacity of the compiste beam can be obtained from moment equilibrium, i.e. by taking moment about the neutral axis which can be expressed as follow:

$M_{u}=\frac{2}{3} F_{c t} y_{c}+\frac{2}{3} F_{t t}\left(h-y_{c}\right)+F_{f r p}\left(h-y_{c}+\frac{1}{2} t_{f r p}\right)$

For control beams $F_{f r p}=0$

Case 2 if $\varepsilon_{c y}<\varepsilon_{c t}<\varepsilon_{c u}$

Compression area of timber beam in this stage may be partially or fully plastic. Thus, the load in compression zone will be divided in two parts. From the condition of equilibrium (Figure 11) it follows that

$F_{c 1 t}+F_{c 2 t}=F_{t t}+F_{f r p}$

$F_{c 1 t}=\frac{\sigma_{c t}+\sigma_{c y}}{2} b_{t} k y_{c}$

$F_{c 2 t}=\frac{1}{2} \sigma_{c y} b_{t}(1-k) y_{c}$

$\frac{\varepsilon_{c t}}{y_{c}}=\frac{\varepsilon_{t}}{h-y_{c}}=\frac{\varepsilon_{c y}}{y_{c}(1-k)}=\frac{\varepsilon_{f r p}}{h+d-y_{c}}$

From the Bazan-Buchanan law

$\sigma_{c t}=\sigma_{c y}-m\left(\varepsilon_{c t}-\varepsilon_{c y}\right)$

$\mathrm{m}$ represents the slop of the plastic zone in the model proposed by Bazan-Buchannan

$m=\frac{\sigma_{c y}-\sigma_{c u}}{\varepsilon_{c t u}-\varepsilon_{c y}}$ 


$$
\begin{aligned}
M_{u}= & \sigma_{c y} b_{t}\left(\frac{k y_{c}{ }^{2}}{2}-\frac{k^{2} y_{c}{ }^{2}}{3}\right)+\sigma_{c t} b_{t}\left(\frac{k y_{c}{ }^{2}}{2}-\frac{k^{2} y_{c}{ }^{2}}{6}\right)+\left(\sigma_{c t}+\sigma_{c y}\right) b_{t} k(1-k) \frac{y_{c}{ }^{2}}{3} \\
& +\frac{1}{3} \sigma_{t t} b_{t}\left(h-y_{c}\right)^{2}+\sigma_{f r p} b_{f r p} t_{f r p}\left(h-y_{c}+\frac{t_{f r p}}{2}\right)
\end{aligned}
$$

The values associated to the above parameters are obtained during tensile and compression tests of timber and FRP as explained in Section 2 as well as tested strengthened beams explained in Section 5. Using those values, the location of $y_{c}$ determined and accordingly the ultimate bending capacity and ultimate load of each beam have been calculated using Eq. (13) and Eq. (20) and results as tabulated in Table 7. The analytical prediction of ultimate bending moment and load carrying capacity for all specimens are also compared against the experimental results. From Table 7, it can be seen that the discrepancy between predicated ultimate bending moment and failure loads against test results varies between $-9 \%$ to $+12 \%$ which might due to uncertain material heterogeneity and model simplifications.

\begin{tabular}{|c|c|c|c|c|c|c|c|c|c|}
\hline Member & $\begin{array}{l}y_{c} \text { Exp. } \\
(\mathrm{mm})\end{array}$ & $\begin{array}{l}y_{c} \text { anal. } \\
(\mathrm{mm})\end{array}$ & $\frac{y_{c \text { Exp. }}}{y_{c} \text { anal. }}$ & $\begin{array}{l}M_{u \text { Exp. }} \\
(k N . m)\end{array}$ & $\begin{array}{l}M_{u \text { anal. }} \\
(k N . m)\end{array}$ & $\frac{M_{u \text { Exp. }}}{M_{u \text { anal. }}}$ & $\begin{array}{l}P_{u \text { Exp. }} . \\
(k N)\end{array}$ & $\begin{array}{l}P_{u \text { anal. }} \\
(k N)\end{array}$ & $\begin{array}{ll}P_{u} \text { Exp. } \\
P_{u} \text { anal. }\end{array}$ \\
\hline B1 & 45.00 & 45.00 & 1.00 & 1.84 & 1.67 & 1.10 & 6.82 & 6.20 & 1.10 \\
\hline B2 & 45.00 & 45.00 & 1.00 & 2.12 & 1.91 & 1.11 & 7.86 & 7.07 & 1.11 \\
\hline B3 & 46.28 & 48.33 & 0.96 & 3.03 & 3.09 & 0.98 & 11.22 & 11.45 & 0.98 \\
\hline B4 & 47.46 & 51.67 & 0.92 & 3.22 & 3.17 & 1.01 & 11.91 & 11.74 & 1.01 \\
\hline B5 & 47.46 & 52.51 & 0.90 & 4.79 & 5.18 & 0.93 & 17.75 & 19.18 & 0.93 \\
\hline B6 & 47.04 & 50.00 & 0.94 & 4.03 & 4.43 & 0.91 & 14.92 & 16.42 & 0.91 \\
\hline B7 & 47.04 & 50.63 & 0.93 & 4.94 & 5.35 & 0.92 & 18.29 & 19.83 & 0.92 \\
\hline B8 & 48.86 & 53.99 & 0.91 & 5.26 & 4.68 & 1.12 & 19.48 & 17.35 & 1.12 \\
\hline
\end{tabular}

Table 7 Experimental versus analytical results

\section{Conclusion}

The main intention of the presented work was to investigate the feasibility of strengthening glulam beams by carbon fibre reinforced polymer composites and to examine the effect of bond geometries on the ultimate flexural capacity, stiffness, 
deflection, and failure mode of FRP strengthened beam. To achieve these outcomes, eight timber beams were tested under monotonic load in four-point bending test. Results of the tests showed that significant improvement in ultimate flexural strength and stiffness can be achieved by reinforcing glulam beams with carbon fibre sheets. The main findings from this study can be summarised as:

- The application of CFRP sheets demonstrated that if the bond thickness is large enough the stiffness of composite beams enhances leading to reduce deflection of strengthened beams. Specimens which were strengthened with more plies of FRP exhibited more ductile behaviour and failed gradually. It was also observed that with the increase of the bond width and length, the ultimate bending strength increases, and conversely mid-span defection decreases, signifying that the reinforcement leads to higher stiffness values.

- Experiments showed that failure of the FRP strengthened timber beams occurred when maximum strain in the FRP was approximately $0.6 \%$ which is around half of the rupture strain of the CFRP sheets. Therefore, the ultimate flexural strength of reinforced timber beam would not be dependent to the tensile strength of fibre composites only; but instead timber mechanical properties must always be considered for both ultimate and serviceability limit state designs. In addition, it was observed that specimens with lower FRP-to-timber width ratio exhibited higher strain at failure compared with samples in which such ratio was larger. Non-uniform stress distribution along width and local shear stress concentrations are characterised as the main reasons for this observation. 
- When all results considered, it was observed that stiffness of strengthened timber beams increased between $31 \%$ to $64 \%$.

- A noticeable decrease in shear stress at failure was obtained when the bond length and bond width increased. This enhancement provides improved behaviour at failure leading a more ductile collapse. That is because, shear stress transfers within the bond more uniformly and the strengthened timber beam will not collapse completely since FRP prevents crack opening and restricts local rupture.

- Some of samples initially failed due to crack propagation in the longitudinal direction of section. Natural defect like knots found to be the main reason for that occurrence. FRP strips can be used to control the existing cracks and delay their growth. Therefore, an additional shear-strengthening system may be required; nevertheless, this could be a new parameter that needs to be developed in the future in another sampling tests.

- A simple analytical model with a higher accuracy for predicting flexural strength and load carrying capacity of strengthened timber beams have been established. A comparative analysis of the results of the experimental tests results and those predicted from the analytical model demonstrated the capability of the model in prediction of the ultimate bending strength and ultimate load carrying capacity.

- The scope of the present study is limited to results of experimental tests; however, further work still requires to be performed to introduce other parameters such as environmental conditions, moisture content, timber surface treatment etc. and their impact on the performance and structural behaviour of FRP externally bonded to timber beams. 


\section{Acknowledgement}

The authors wish to acknowledge the support provided by Australian Government

Research Training Program Scholarship.

\section{References}

1. Biscaia, H.C., et al., Prediction of the interfacial performance of CFRP laminates and old timber bonded joints with different strengthening techniques. Composites Part B: Engineering, 2017. 108: p. 1-17.

2. Diab, H.M. and O.A. Farghal, Bond strength and effective bond length of FRP sheets/plates bonded to concrete considering the type of adhesive layer. Composites Part B: Engineering, 2014. 58: p. 618-624.

3. Serbescu, A., et al., Standardised double-shear test for determining bond of FRP to concrete and corresponding model development. Composites Part B: Engineering, 2013. 55: p. 277-297.

4. Biscaia, H.C., et al., Bond-slip model for FRP-to-concrete bonded joints under external compression. Composites Part B: Engineering, 2015. 80: p. 246-259.

5. de la Rosa García, P., et al., Bending reinforcement of timber beams with composite carbon fiber and basalt fiber materials. Composites Part B: Engineering, 2013. 55: p. 528-536.

6. Raftery, G.M. and A.M. Harte, Nonlinear numerical modelling of FRP reinforced glued laminated timber. Composites Part B: Engineering, 2013. 52: p. 40-50.

7. Borri, A., et al., Reinforcement of wood with natural fibers. Composites Part B: Engineering, 2013. 53: p. 1-8.

8. Raftery, G.M. and P.D. Rodd, FRP reinforcement of low-grade glulam timber bonded with wood adhesive. Construction and Building Materials, 2015. 91: p. 116-125.

9. Valipour, H.R. and K. Crews, Efficient finite element modelling of timber beams strengthened with bonded fibre reinforced polymers. Construction and Building Materials, 2011. 25(8): p. 3291-3300.

10. Coronado, C., Characterization, modeling and size effect of concrete-epoxy interfaces, in Department of Civil and Environmental Engineering. 2006, The Pennsylvania State University.

11. Biscaia, H.C., et al., Flexural Strengthening of Old Timber Floors with Laminated Carbon Fiber-Reinforced Polymers. Journal of Composites for Construction, 2016. 21(1): p. 04016073.

12. Wu, Z. and S. Hemdan. Debonding in FRP Strengthened Flexural Members with Different Shear-Span Ratios. in Proceeding of the 7th International Symposium on Fiber Reinforced Composite Reinforcement for Concrete Structures. 2005. Michigan, USA.

13. Thorhallsson, E.R., et al., Strength and stiffness of glulam beams reinforced with glass and basalt fibres. Composites Part B: Engineering, 2017. 115: p. 300-307.

14. Porteous, J. and A. Kermani, Structural timber design to Eurocode 5. 2013: John Wiley \& Sons.

15. Thelandersson, S. and H.J. Larsen, Timber engineering. 2003: John Wiley \& Sons.

16. Carling, O., Limtra: arkitektmanual. 1995, Stockholm: Svenskt limtra AB.

17. Corradi, M., et al., Uncertainty analysis of FRP reinforced timber beams. Composites Part B: Engineering, 2017. 113: p. 174-184. 
18. Vallée, T., et al., Influence of stress-reduction methods on the strength of adhesively bonded joints composed of orthotropic brittle adherends. International Journal of Adhesion and Adhesives, 2010. 30(7): p. 583-594.

19. Vahedian, A., et al., Modelling of Factors Affecting Bond Strength of Fibre Reinforced Polymer Externally Bonded to Timber and Concrete. World Academy of Science, Engineering and Technology, International Journal of Civil, Environmental, Structural, Construction and Architectural Engineering, 2017. 11(12): p. 1567-1574.

20. Vahedian, A., et al., Analysis of externally bonded Carbon Fibre Reinforced Polymers sheet to timber interface. Composite Structures, 2018. 191.

21. Vahedian, A., et al., Effective bond length and bond behaviour of FRP externally bonded to timber. Construction and Building Materials, 2017. 151: p. 742-754.

22. $\mathrm{Xu}, \mathrm{T}$., et al., Finite element analysis of width effect in interface debonding of FRP plate bonded to concrete. Finite Elements in Analysis and Design, 2015. 93: p. 30-41.

23. Borri, A., et al., $A$ method for flexural reinforcement of old wood beams with CFRP materials. Composites Part B: Engineering, 2005. 36(2): p. 143-153.

24. Valluzzi, M.R., et al., Multi-scale characterization of moisture and thermal cycle effects on composite-to-timber strengthening. Construction and Building Materials, 2016. 102: p. 1070-1083.

25. Lyons, J.S. and M.R. Ahmed, Factors affecting the bond between polymer composites and wood. Journal of Reinforced Plastics and composites, 2005. 24(4): p. 405-412.

26. Raftery, G.M., et al., Bonding of FRP materials to wood using thin epoxy gluelines. International Journal of Adhesion and Adhesives, 2009. 29(5): p. 580-588.

27. Wan, J., et al., Experimental Investigation on FRP-to-Timber Bonded Interfaces. Journal of Composites for Construction, 2013.

28. Wan, J., An investigation of FRP-to-timber bonded interfaces, in Civil Engineering. 2014, The University of Hong Kong Pokfulam, Hong Kong.

29. Gentile, C., et al., Timber beams strengthened with GFRP bars: development and applications. Journal of Composites for Construction, 2002. 6(1): p. 11-20.

30. Khelifa, M. and A. Celzard, Numerical analysis of flexural strengthening of timber beams reinforced with CFRP strips. Composite Structures, 2014. 111: p. 393-400.

31. De Jesus, A.M.P., et al., Analysis of solid wood beams strengthened with CFRP laminates of distinct lengths. Construction and Building Materials, 2012. 35: p. 817828.

32. BS_EN_408, Timber structures - structural timber and glued laminated timber determination of some physical and mechanical properties, in BS EN 408:2010. 2010, British Standards Institution: London, UK,.

33. ASTM-D2093-03, Standard Practice for Preparation of Surfaces of Plastics Prior to Adhesive Bonding., in American Society for Testing and Materials. 2003, West Conshohocken, PA: USA.

34. BSI, Structural Adhesives - Guidelines for the Surface Preparation of Plastics, in BS EN 1840. 1995, British Standards Institution: London, UK,.

35. ASTM-D3039/D3039M, Standard test method for tensile properties of polymer matrix composite materials, in American Society for Testing and Materials. 2014, West Conshohocken, PA: USA,.

36. AS/NZS-4063.1, Characterization of structural timber Part 1: Test methods, in Australian/New Zealand Standard ${ }^{T M}$. 2010, Joint Technical Committee TM-001, Timber Structures: Australia.

37. $\quad$ Sikadur ${ }^{\circledR}$-330. 2-part epoxy impregnation resin, Product Data Sheet. 2015.

38. Hollaway, L.C. and J.-G. Teng, Strengthening and rehabilitation of civil infrastructures using fibre-reinforced polymer (FRP) composites. 2008, North America by CRC Press: Elsevier Reference Monographs. 
39. Franco, A. and G. Royer Carfagni, Effective bond length of FRP stiffeners. International Journal of Non-Linear Mechanics, 2014. 60: p. 46-57.

40. Yuan, H., et al., Full-range behavior of FRP-to-concrete bonded joints. Engineering Structures, 2004. 26(5): p. 553-565.

41. Dai, J., et al., Development of the nonlinear bond stress-slip model of fiber reinforced plastics sheet-concrete interfaces with a simple method. Journal of Composites for Construction, 2005. 9(1): p. 52-62.

42. Chen, J. and W. Pan, Three dimensional stress distribution in FRP-to-concrete bond test specimens. Construction and Building Materials, 2006. 20(1): p. 46-58.

43. Ye, F. and J. Yao, A 3D Finite Element Study on The Effect of FRP Plate Width on Interfacial Stress between FRP and Concrete [J]. Bulletin of Science and Technology, 2008. 24(6): p. 853-859.

44. Bazan, I.M.M., Ultimate bending strength of timber beams. 1980, Technical University of Nova Scotia. 


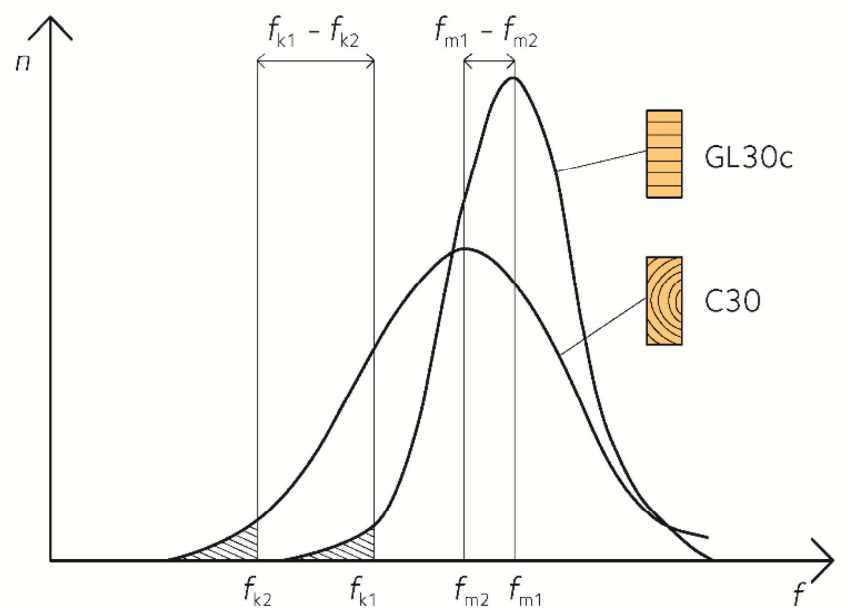

Figure 1 Strength properties of standard building timber and glulam. The $f$ axis denotes the strength and the $n$ axis is number of samples tested [10]. 

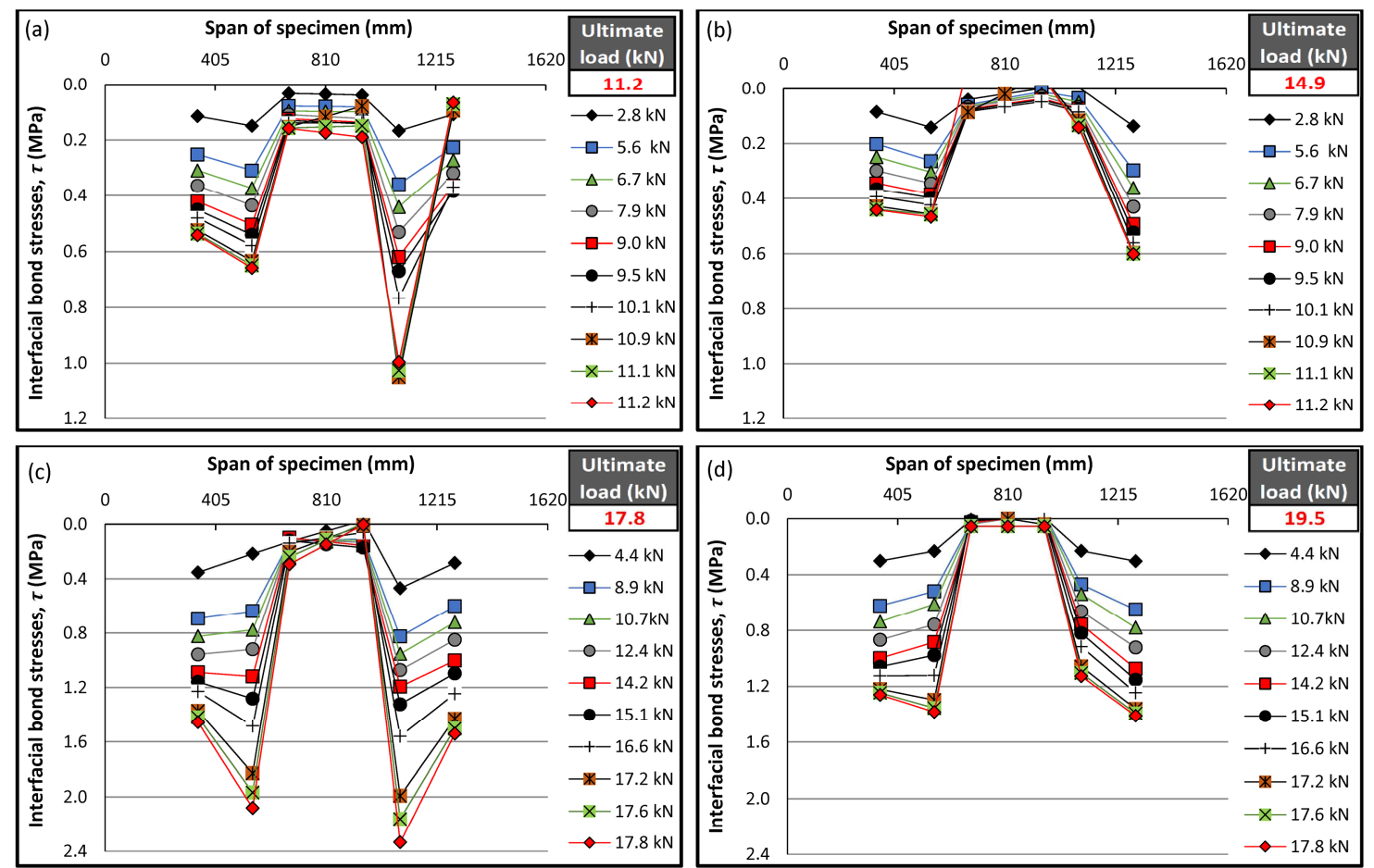

Figure 10 Shear stress as function of relative load level and bond width for selected specimens, (a) B3, (b) B6, (c) B5 and (d) B8 


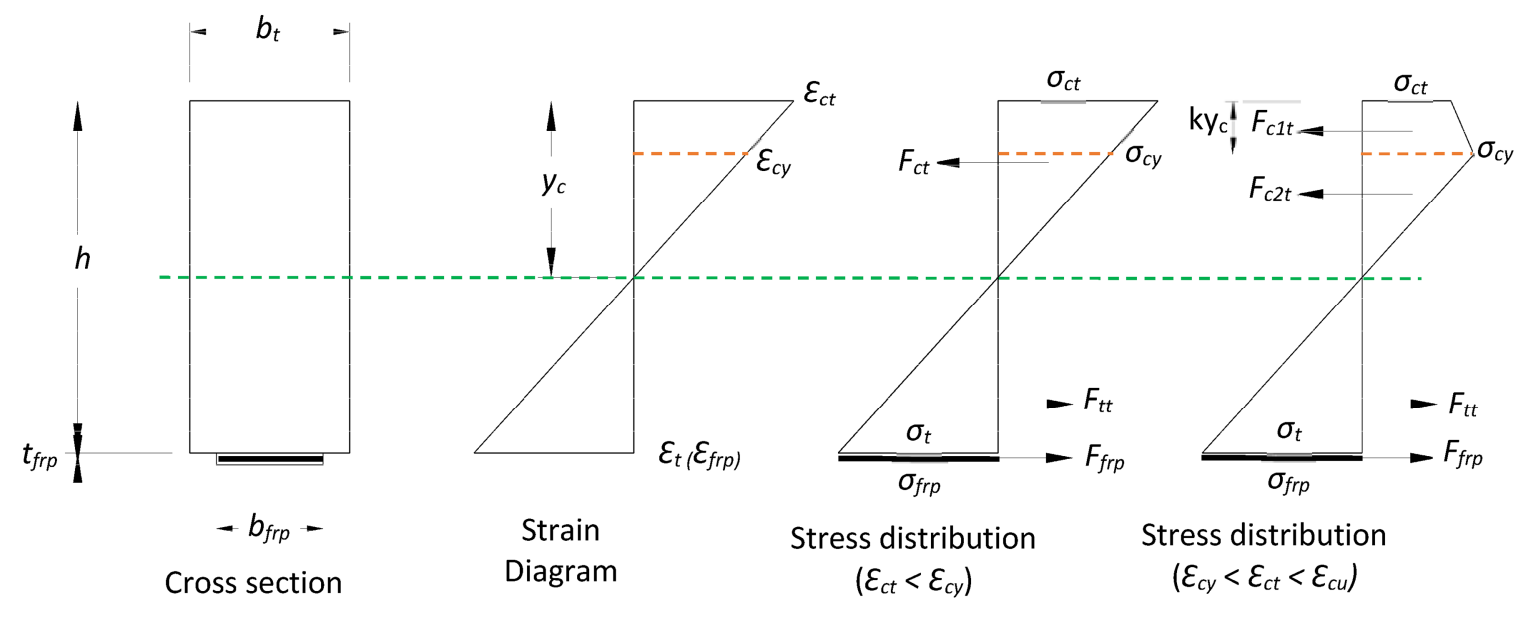

Figure 11 Elastic and ultimate limit scheme of a timber section 
(a)
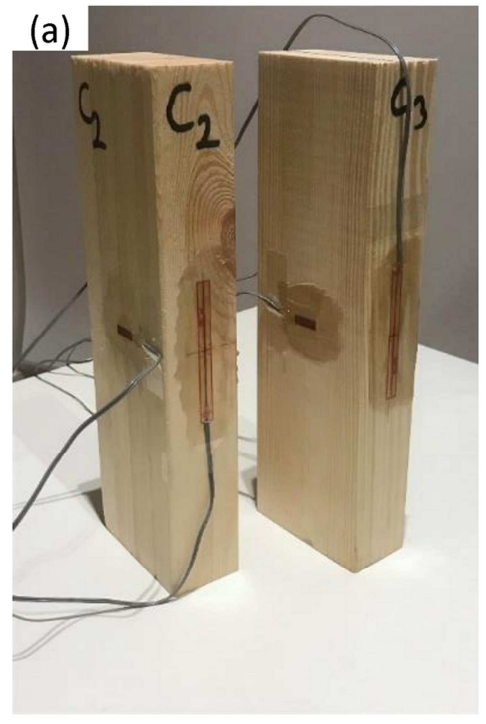

(b)

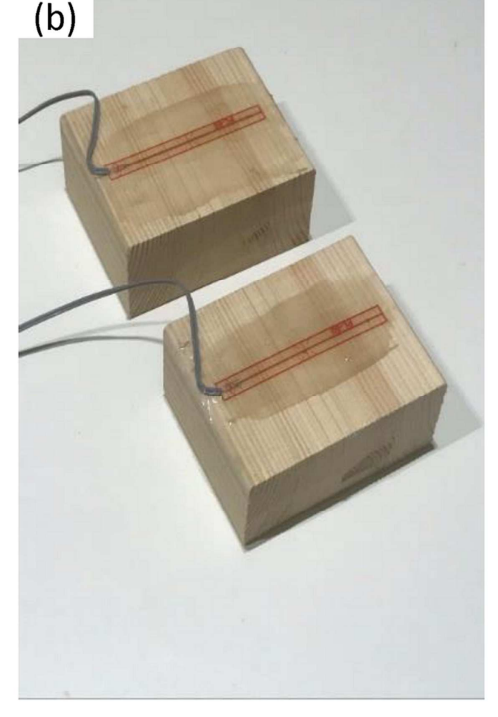

(c)

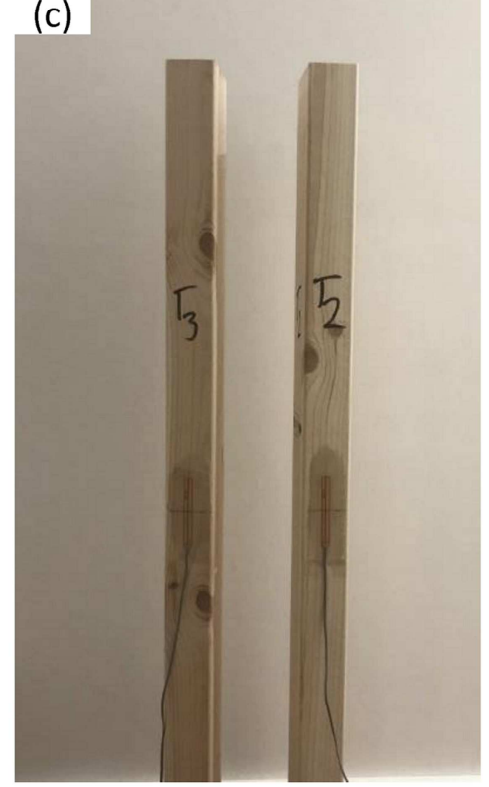

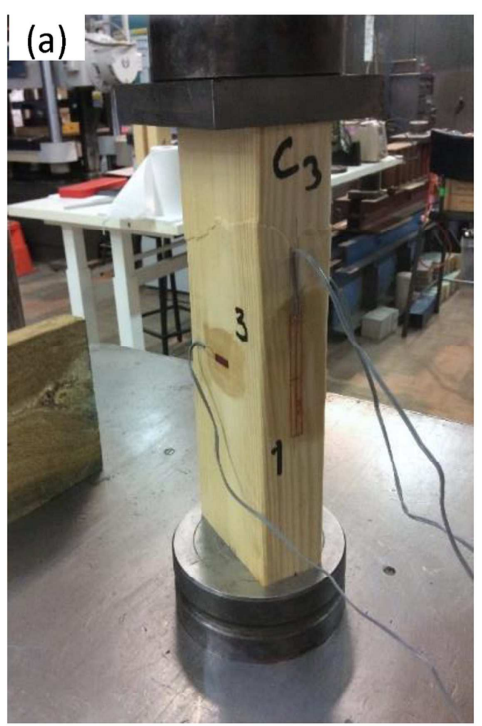
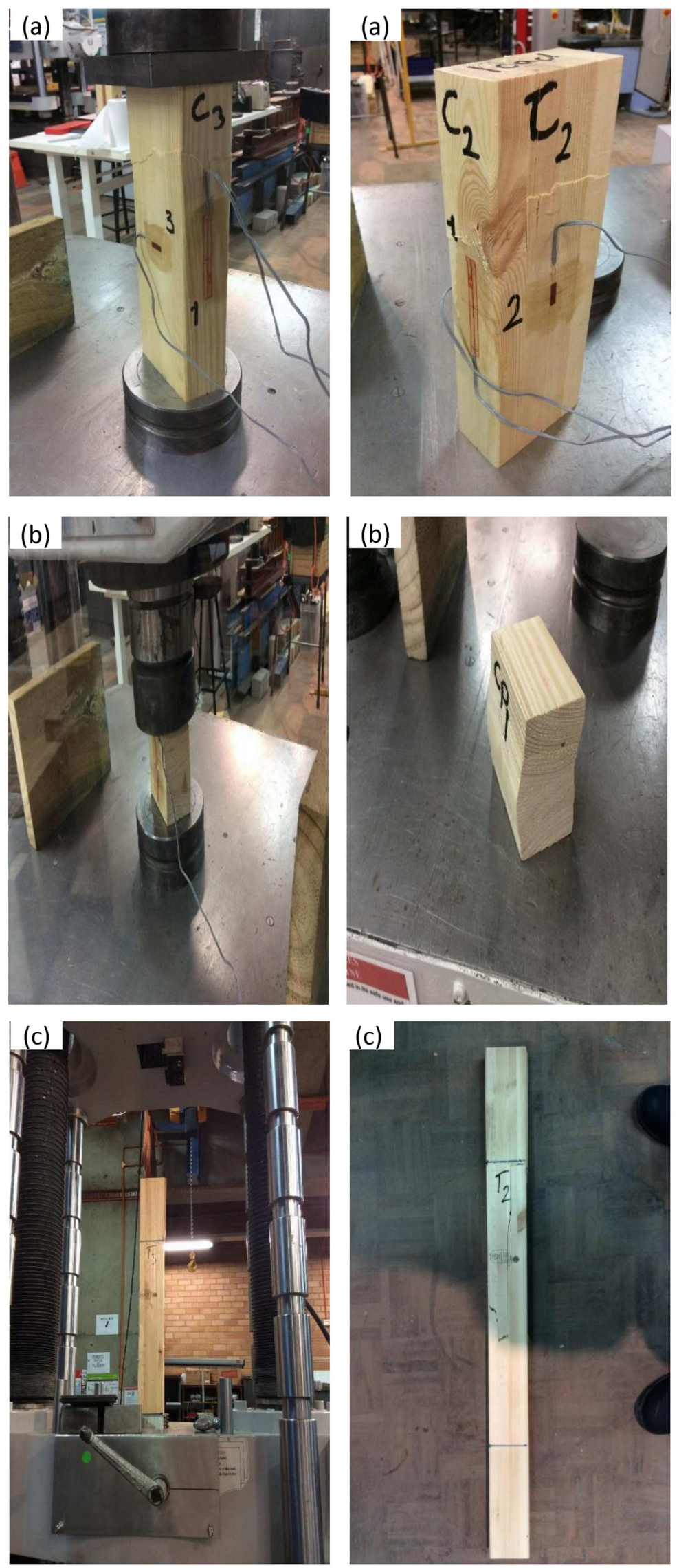

Figure 2 Timber specimens test in progress; (a) compressive test parallel to grain, (b) compressive test perpendicular to grain, and (c) tensile test parallel to grain 

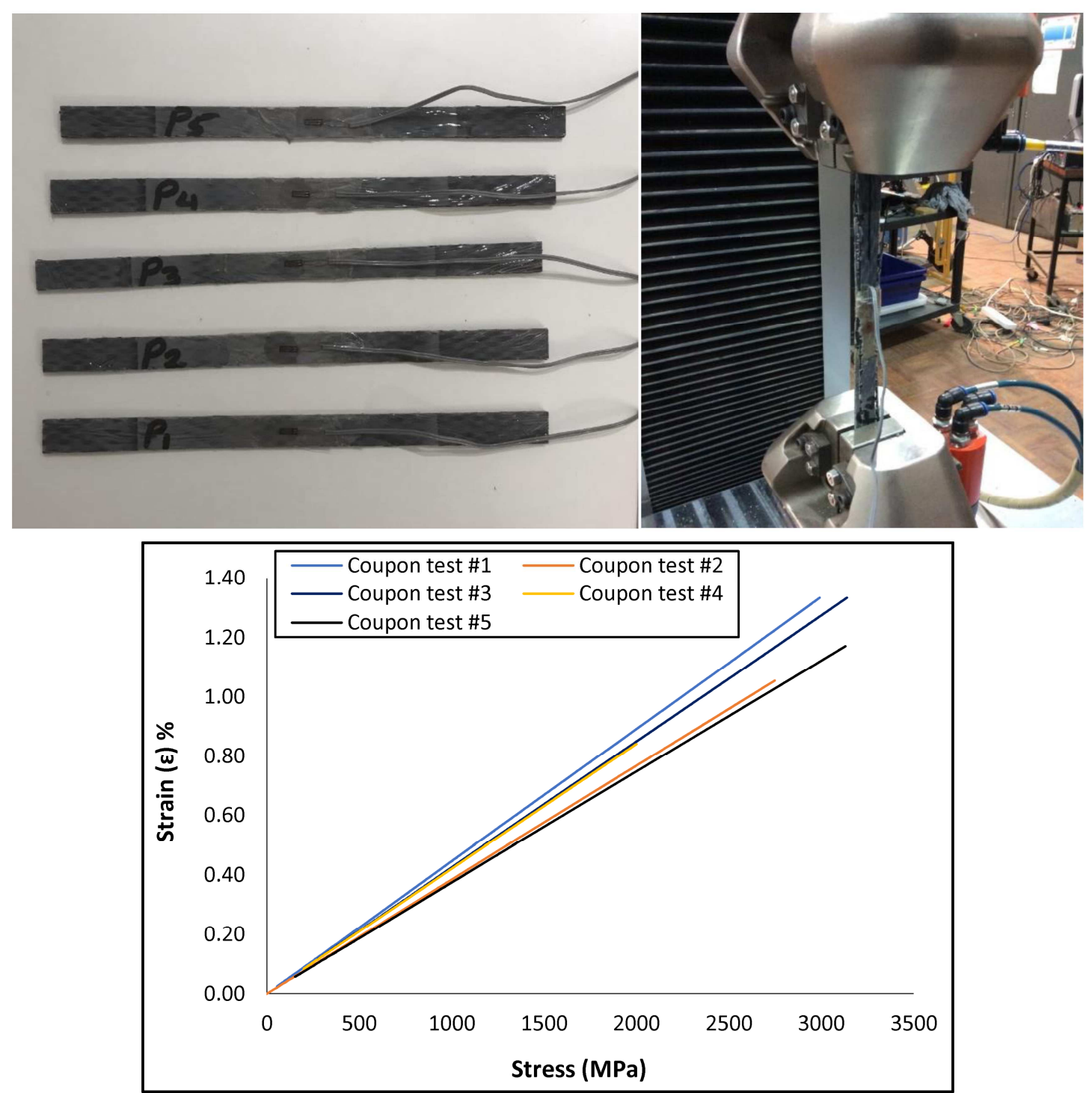

Figure 3 FRP coupon test specimens and results. 


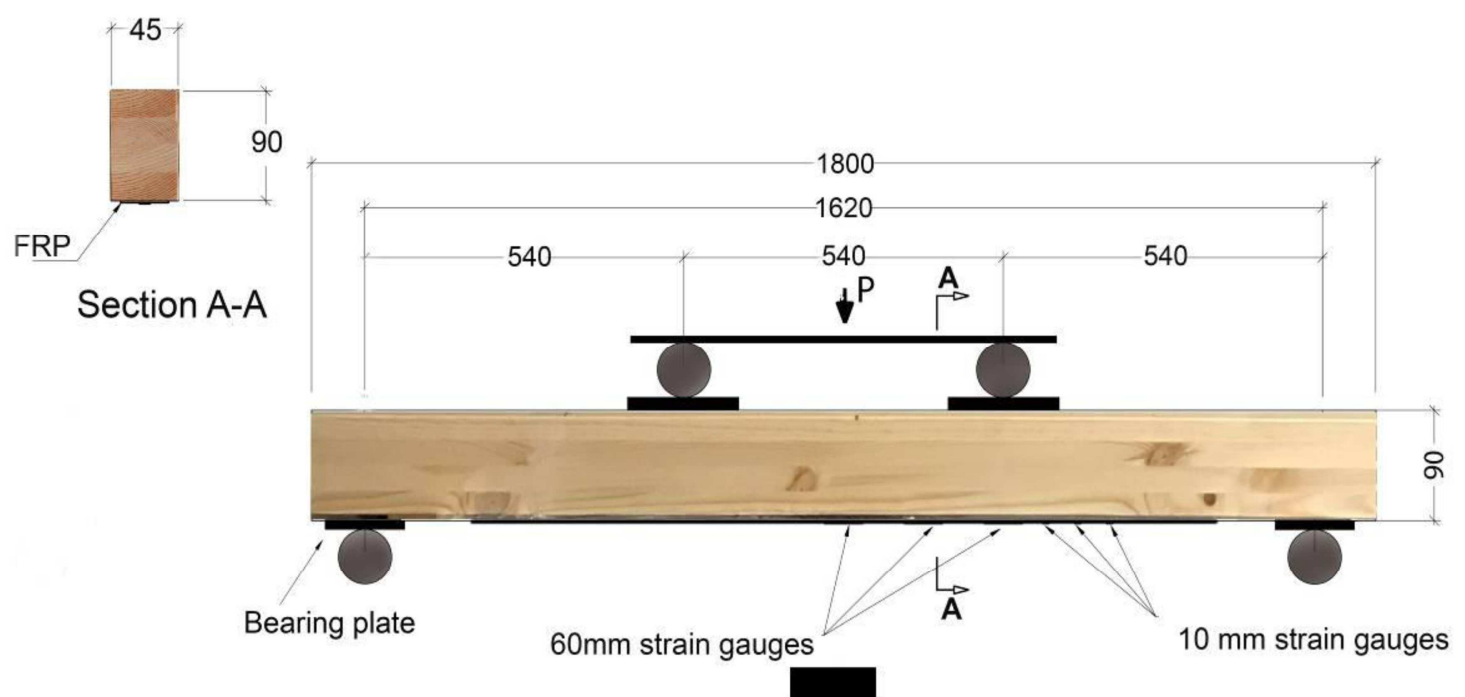

A laser displacement sensor
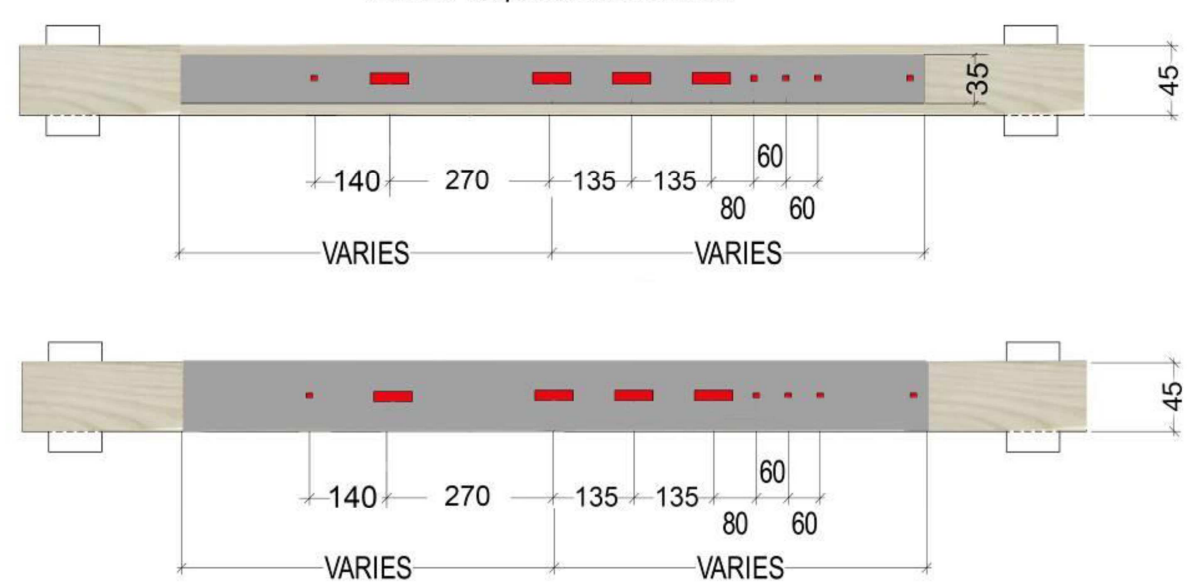

Figure 4 Detail of test set-up; a schematic view, (a) $45 \mathrm{~mm}$ bond width, (b) $30 \mathrm{~mm}$ bond width 

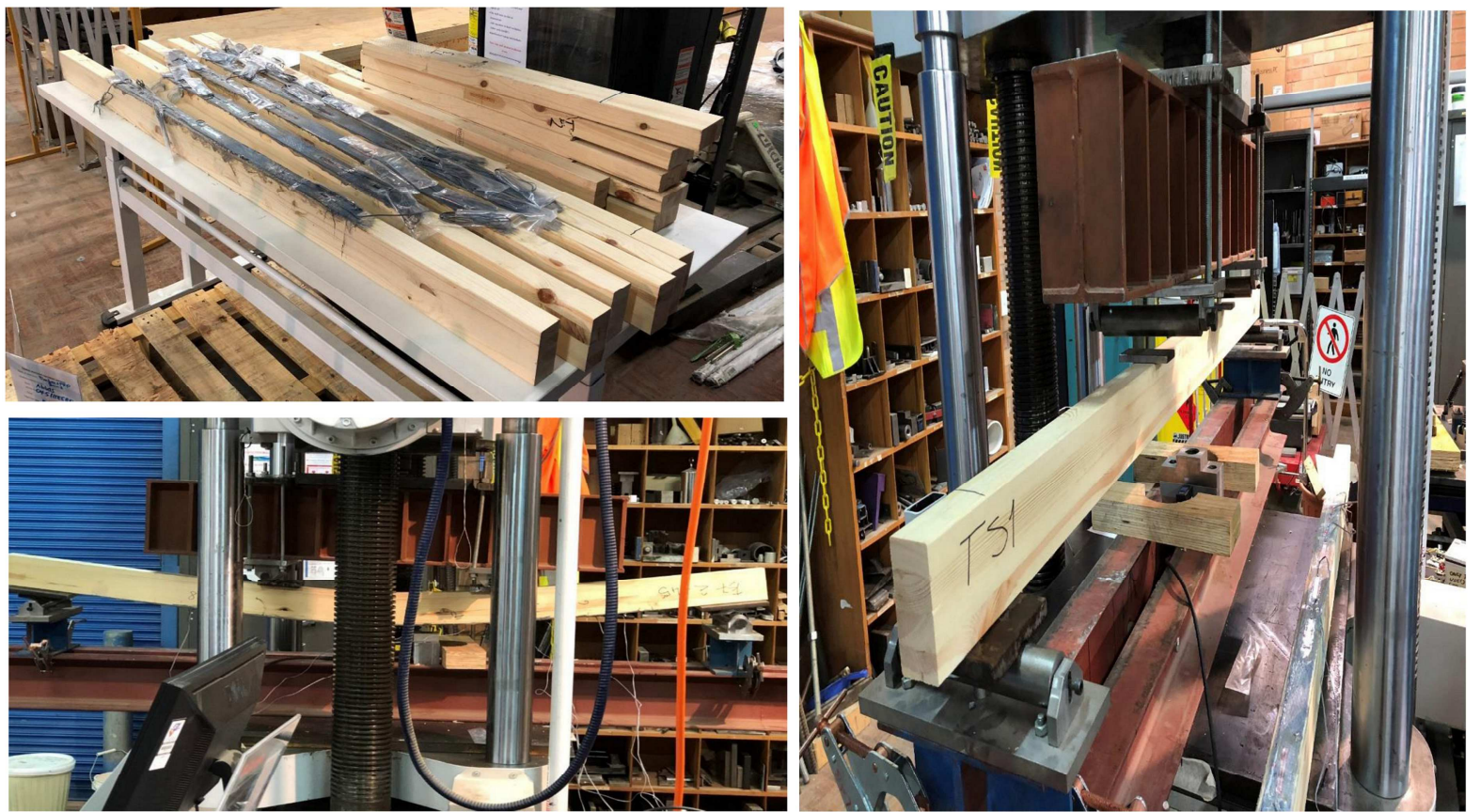

Figure 5 Fabricated FRP-to-timber beam 

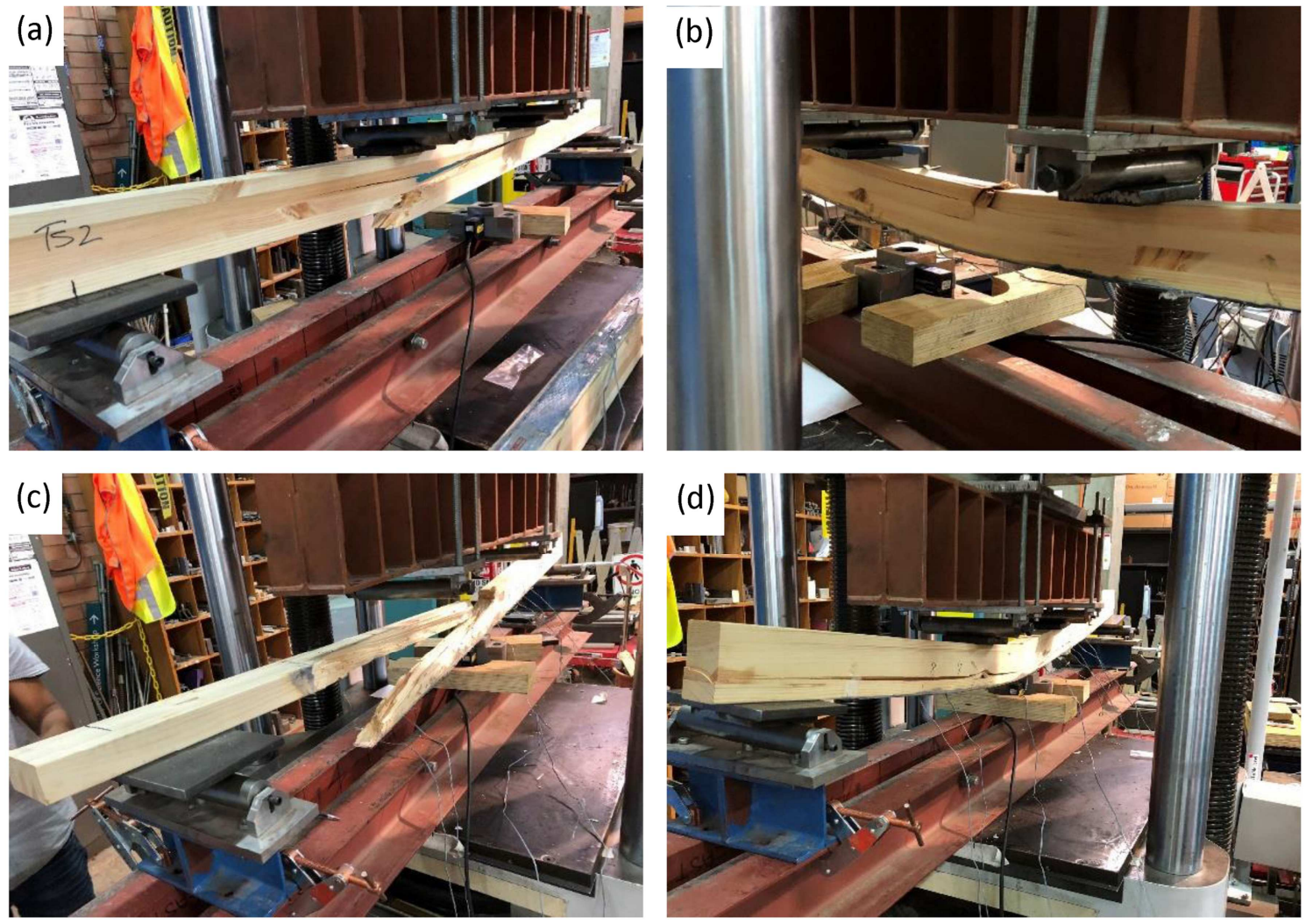

Figure 6 Failure mode of timber beams; (a) B2 (TS2), (b) B4 (TS4), (c) B6 (TS5) and (d) B7 (TS7) 


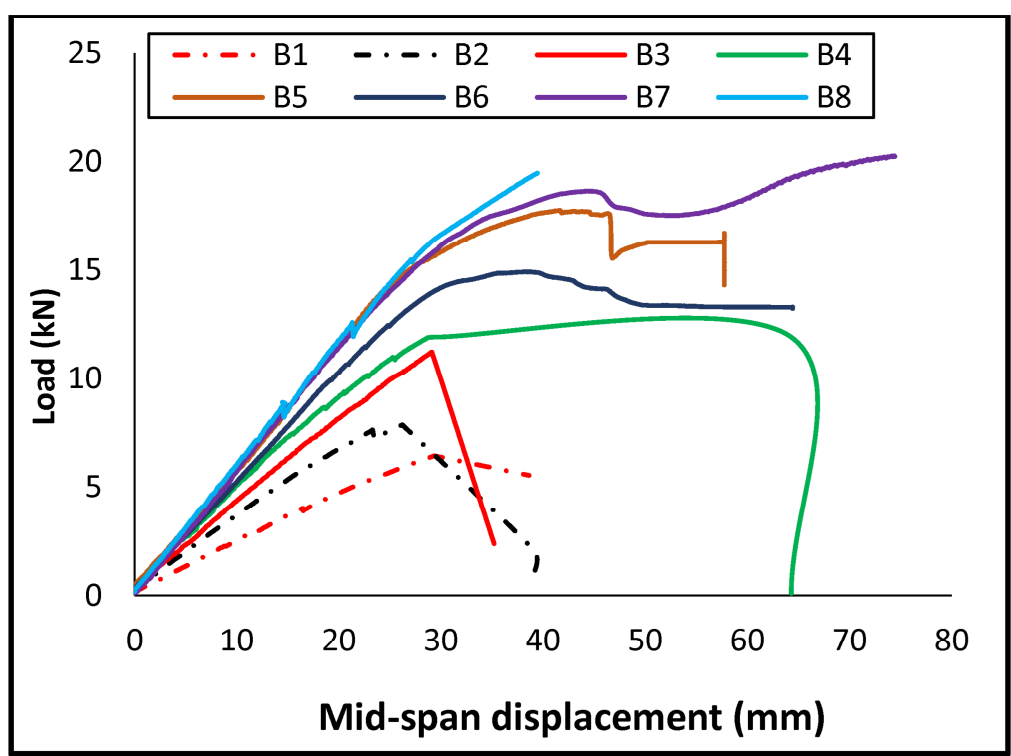

Figure 7 Load-displacement curves (mid-span measures). 

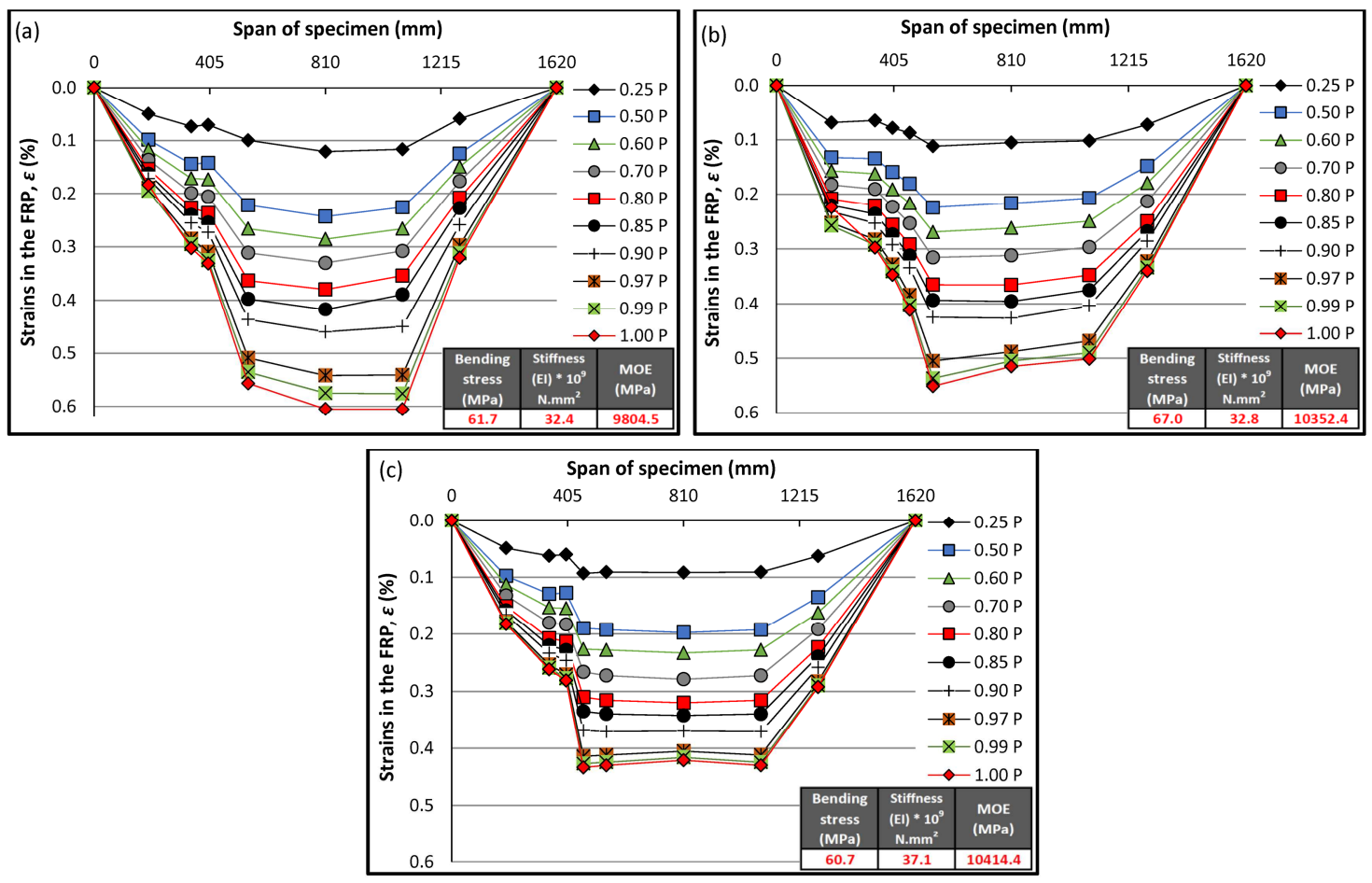

Figure 8 Strains in the CFRP sheets, (a) B5 (TS8), (b) B7 (TS7) and (c) B8 (TS6) 

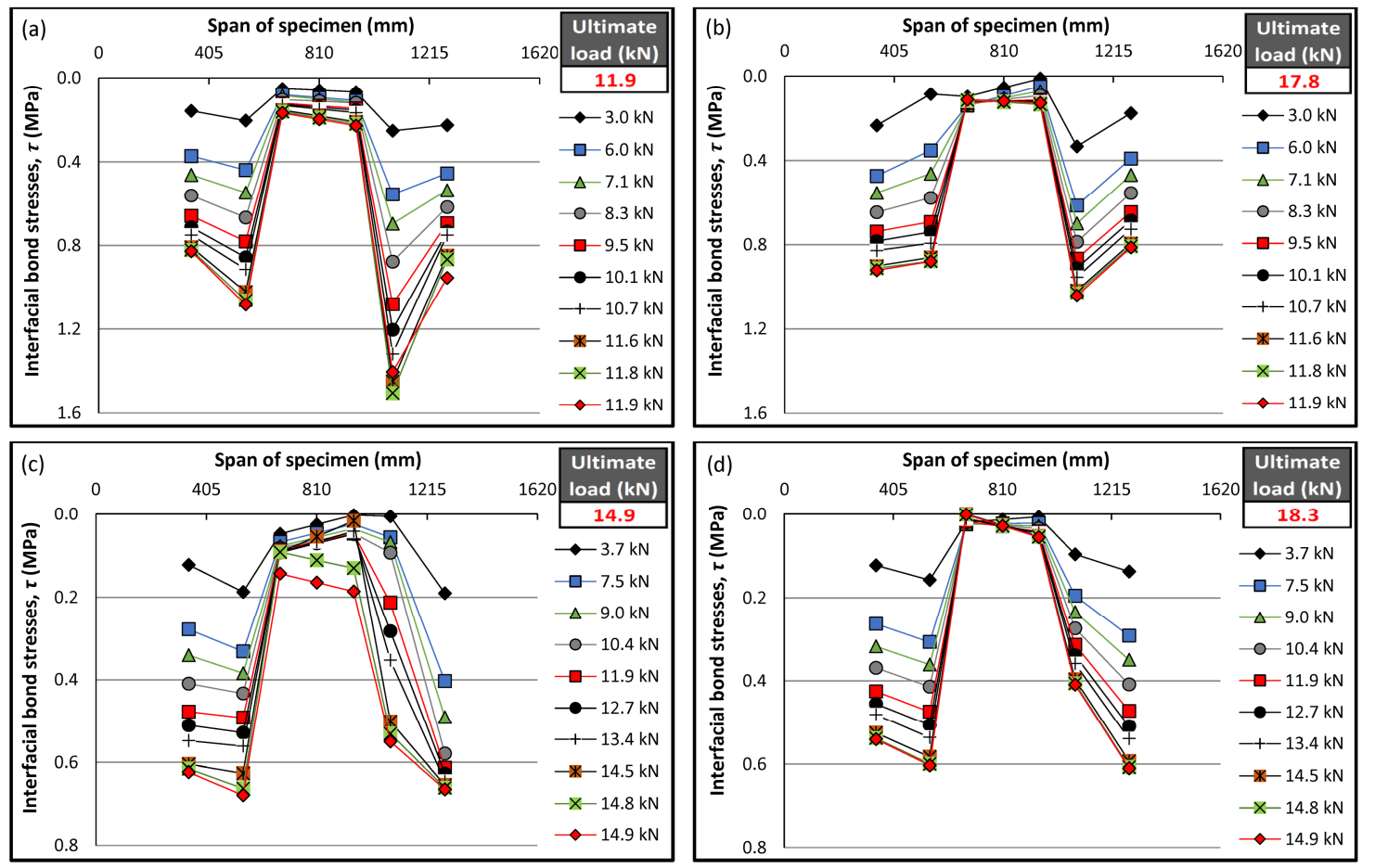

Figure 9 Shear stress as function of relative load level and bond length in the interface for selected specimens, (a) B4, (b) B5, (c) B6 and (d) B7 